\title{
The Development Planning Scheme of the Transmission Lines Based on LCC
}

\author{
$\mathrm{Xu} \mathrm{Yan}$ \\ State Key Laboratory of Alternate Electrical Power \\ System with Renewable Energy Source \\ North China Electric Power University \\ Baoding, China \\ xuyan@ncepubd.edu.cn
}

\author{
Chi Cheng \\ State Key Laboratory of Alternate Electrical Power \\ System with Renewable Energy Source \\ North China Electric Power University \\ Baoding, China \\ 2302682728@qq.com
}

\begin{abstract}
Life Cycle Cost Management is a quantitative analysis method. During the grid operation, load growth causing reduced reliability phenomenon such as some lines overloads, electric power enterprises to re-plan and transformate transmission line to ensure the reliability. In this context, in order to reduce the investment cost of the transformation of the power companies and the loss of power users, the use of life-cycle costs, Monte Carlo simulation and DC load flow analysis to establish development plan optimization model of transmission line, quantitative analysis cost of each stage, seek the minimum LCC cost scheme, ensuring reliability while reducing the unnecessary loss of power grid enterprises and customers, improve economic efficiency, raise the overall level of lean management and scientific decision-making At last, in the numerical example, using IEEE39 node to simulate grid operation, comparing different improved circuit development planning, which proves the feasibility and effectiveness of the method.
\end{abstract}

Keywords- Transmission Lines, Life cycle cost management;LCC model;Monte Carlo simulation;DC load flow analysis;

\section{INTRODUCTION}

Under the market environment, the basic task of transmission line development planning is to meet a certain level of reliability, as far as possible the development of power system economic. Existing transmission lines considering the principle of $\mathrm{N}-1$ and other indexes in the planning and design, But with the power load growth, some lines have been in operation for many years will cause heavy load or overload phenomenon when some components out of run, causing the network reliability reduced. Power companies often have to take the load reduction method ensures the safe operation of the power grid, but large-scale planning grid change is obviously not realistic, the practice will not only increase the cost of investment in the electricity business, resulting in the loss of electric power companies and the loss of electricity customers. So in order to improve reliability, commitment to serve the purpose of electricity customers, as well as the normal safe operation of the grid for the future, LCC method can be used to find the weak points of the grid development plan.
Reference 1 consider power transmission system planning based on grey chance constrained programming, which consider more uncertainty; Reference 2 consider transmission system expansion planning of joint operation of wind farms, Reference 3,4 consider energy storage systems, and intermittent power supply; Reference 5 consider static security risk.

But the above planning method stresses more on reliability than economy, although some consider both, but only considering the cost of each stage, lack of systematic and holistic. This paper proposed to adopt life-cycle management approach, focusing on the entire cycle cost of equipment, Reference 6,7 involve LCC basic concepts and models of transmission lines designment; Reference 8 concern about the motivation for impacting LCC in transmission line design, use Spearman correlation coefficient to measure the relationship between the various cost drivers and LCC. Reference 9 put forward a kind of UHV DC transmission line conductor selection model based on LCC; Reference 10 according to the whole life cycle cost model for the power transformer, put forward a comprehensive sensitivity analysis method.

First of all, the pursuit of equipment life cycle cost is the lowest, for example, in the choice of the procurement of equipment, not a simple cheap, must also consider a series of cost after acquisition, in fact, the purchase of the lowest price is not necessarily the lowest life cycle cost; Secondly, reliability has been considered in the planning stage, the reliability management migration to the initial stage of equipment management.

\section{THE DEVELOPMENT PLANNING MODEL OF THE TRANSMISSION LINES BASED ON LCC}

LCC model development planning of transmission lines can be expressed as:

$$
L C C=C I+C O+C M+C F+C D
$$

LCC is a full life-cycle costs; $C I$ is the cost of investment, including purchasing cost, installation debugging and other fees; $\mathrm{CO}$ is operating costs, including the loss cost and artificial cost inspection; $C M$ is the maintenance cost, including periodic maintenance and test cost; $C F$ is the cost of failure; $C D$ is a retired disposal costs, including demolition, equipment cost and disposal 
of artificial transportation cost. The cost of failure $C F$ is composed of direct fault cost and indirect fault cost, direct fault cost is the direct economic losses cause multiple fault system, usually refers to the power loss, can be used for cost $(U E C)$ to indicate the fault. Indirect costs include compensation costs failure, adverse effects on the community and the company into disrepute and other indirect costs, but due to the calculation of indirect costs is still inconclusive, with different economic conditions, social conditions and grid conditions in different countries and others have relationship can only make reference to the relevant provisions of the approximation is calculated, or direct proportion to the value of the cost of failure will be, so this article discusses only the direct cost of failure is failure costs,

Reference LCC basic model, establish following optimization model:

$\min L C C=\min \left\{C I+(C O+C M+C F) \times K_{1}+C D \times K_{2}\right\}$

$C I$ is the construction cost of the new lines, $C I=\sum_{i \in L_{i}} \sum_{j \in L_{j}} l_{i j} \times c_{l} l_{i j}$ is the distance between bus $i$ and bus $j, c_{l}$ is line construction cost of per unit length, contains the purchase cost, installation and debugging cost etc. $C O$ is transmission lines operating cost, in different development planning scheme of transmission lines, artificial patrol cost have little difference, therefore this article omitted, only consider the loss cost. $C O=\sum_{i \in L} \sum_{j \in L} \beta P_{j}^{2} l_{i j}, \beta$ is line loss conversion coefficient, $\beta=\beta_{1} \beta_{2} \beta_{3} /\left(U^{2} \cos ^{2} \varphi\right), \beta_{1}$ is the price of electricity, $\beta_{2}$ is line resistance per unit length, $\beta_{3}$ is annual maximum loss hours of network, $U$ is line voltage; $C M$ is transmission line maintenance cost, $C M=\delta C I, \delta$ is maintenance costs conversion coefficients, most power companies for the supply of equipment maintenance costs are determined based on the total annual cost plans, taking a percentage of the initial investment, $K_{1}$ is the present value of operating year conversion coefficients, $K_{1}=(1+r)^{-n}, r$ is the annual interest rate, $n$ is particular year, vary from 0 to $a, a$ is calculated life; $K_{2}$ is the present value of calculated life conversion coefficients, $K_{2}=(1+r)^{-a} . C F$ is the cost of failure, represented by outages cost, $U E C=E E N S \times C_{\text {price }}, E E N S$ is the expected loss of insufficient power supply, the unit is

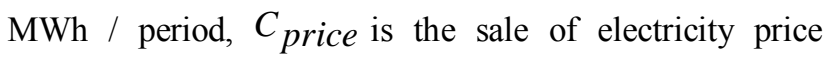
system. So the key to the cost of failure statistics is expected loss of insufficient power supply statistics.

$$
E E N S=\sum_{i=1}^{\mathrm{N}}\left(\sum_{s \in F_{i}} \frac{n(\mathrm{~s}) \mathrm{C}(\mathrm{s})}{N_{i}}\right) \times T_{i}
$$

$\mathrm{N}$ is the number of horizontal load classification, $F_{i}$ is collection of failure state level $i$ load level system, $T_{i}$ is time $\operatorname{span}(\mathrm{h})$ of level $i$ load level system, $n(\mathrm{~s})$ is the number of states $\mathrm{s}$ in the occurrence of sampling. $N_{i}$ is the total number of samples, $C(\mathrm{~s})$ is load reduction(MW) of state s.

As the power enterprises to improve the reliability of the power grid, while taking into account the operation of the economy, as well as electricity electricity customers experience, So in this paper, the model of LCC was established by the method based on the DC power flow optimization model. The purpose is using the LCC method to make power development planning, when line failure occurs, can with target of the minimum amount of load reduction to operation, to ensure the reliability of power supply, to increase enterprises profit.

$$
\begin{aligned}
& \min \sum_{i \in N D} W_{i} C_{i} \\
& \text { s.t. }\left\{\begin{array}{l}
\boldsymbol{P}_{\boldsymbol{l}}=\boldsymbol{A}(\boldsymbol{P G}-\boldsymbol{P D}+\boldsymbol{C}) \\
\sum_{i \in N G} \boldsymbol{P G}_{\boldsymbol{i}}+\sum_{i \in N D} \boldsymbol{C}_{\boldsymbol{i}}=\sum_{i \in N D} \boldsymbol{P} \boldsymbol{D}_{\boldsymbol{i}} \\
\boldsymbol{P} \boldsymbol{G}_{\text {min }} \leq \boldsymbol{P G} \leq \boldsymbol{P} \boldsymbol{G}_{\text {max }} \\
\boldsymbol{0} \leq \boldsymbol{C} \leq \boldsymbol{P D} \\
\left|\boldsymbol{P}_{\boldsymbol{l}}\right| \leq \boldsymbol{P}_{\text {lmax }}
\end{array}\right.
\end{aligned}
$$

The above formula satisfy the power balance, the trend of relationship and branch rated capacity and power generation unit output restricted, the optimal model is established by adopting the method of DC power flow. $\boldsymbol{P}_{\boldsymbol{l}}$ is the line active power flow vector; $\boldsymbol{A}$ is active power flow and bus injection power relationship matrix; $P \boldsymbol{G}$ is the generator output vector; $\boldsymbol{P D}$ is bus load vector; $\boldsymbol{C}$ is bus load abatement; $\boldsymbol{P} \boldsymbol{G}_{\max }$ and $\boldsymbol{P} \boldsymbol{G}_{\boldsymbol{m i n}}$ is the upper and lower limits of the output vector generator; $\boldsymbol{P}_{\text {lmax }}$ is line rated active power vector; $W_{i}$ is weighting factor for importance of bus; $N D$ is load bus collection; $N G$ is bus generator set.

DC trend has $\boldsymbol{\theta}=\boldsymbol{X P}, \boldsymbol{P}_{l}=\boldsymbol{B}_{l} \boldsymbol{\Phi}, \boldsymbol{\Phi}=\boldsymbol{A}_{l} \boldsymbol{\theta}$, so Relationship matrix $\boldsymbol{A}$ can be expressed as:

$$
\boldsymbol{A}=\boldsymbol{B}_{l} \boldsymbol{A}_{l} \boldsymbol{X}
$$

$\boldsymbol{B}_{\boldsymbol{l}}$ is Diagonal matrix consist of each branch admittance; $\boldsymbol{A}_{\boldsymbol{l}}$ is Network correlation matrix; $\boldsymbol{\theta}$ is Node voltage phase angle vector; $\boldsymbol{\Phi}$ is phase angle difference vector at both ends of each branch; $\boldsymbol{X}$ is the inverse matrix of Node admittance matrix imaginary part.

\section{TRANSMISSION LINE DEVELOPMENT PLANNING METHOD BASED ON LCC}

Transmission line development plan based on the LCC method steps discussed in this article is divided into two parts: The first part is to find and statistic all the state overloaded lines; The second part is to propose a different solution to overloaded development planning problems caused by load reduction for these lines, re-use LCC model to discuss advantages and disadvantages of of different options. 
For the second part of the line due to overloading caused by load reduction solution is expansion method. What overloaded line capacity is needed, how much capacity expansion, and face a variety of qualified leads to choice, which can form several sets of programs, so by calculating the cost of the various stages of different options, choose the smallest of all the total cost of the program is the best program .

The second part of the following steps:

1. Establish a multi-level load model, and statistic the annual load running data according to the different load level;

2. Select an expansion project;

3. Select a year, and then select a load level of the year, using Monte Carlo simulation method selection system status, Because this paper is concerned with the transmission system planning, so set generator is $100 \%$ reliable, transmission line is divided into two states of normal operation and outage simulation;

4. DC current optimization methods for system analysis, solving linear programming of the minimum load reduction model to minimize the load reduction.

5. Calculate and modify a modified cost index;

6 . Repeat steps 2-5 until all years for all load levels have been calculated.

7. Calculate the running cost, maintenance cost and failure cost, pay attention to the present value of the conversion coefficient;

8. Statistical investment cost and decommissioning disposal costs, calculation program LCC;

9. Repeat steps 2 to 8, until all solutions are counted;

10. Comparison of different schemes of LCC, select the optimal scheme.

\section{NUMERICAL EXAMPLE}

This paper adopts the method of programming LCC development planning with MATLAB for IEEE39 node system. The initial parameters needed for planning as shown in Table 1, the candidate transmission line parameters as shown in table 2.

Table 1. Transmission Lines LCC planning parameters

\begin{tabular}{ccl}
\hline Parameters & \multicolumn{1}{c}{ Meaning } & Numerical \\
\hline$\delta$ & $\begin{array}{c}\text { Maintenance costs conversion } \\
\text { coefficients } /(\%)\end{array}$ & 1.5 \\
\hline$r$ & The annual interest rate/(\%) & 5 \\
\hline$a$ & The whole life cycle /a & 20 \\
\hline $\cos \varphi$ & Power factor & 0.9 \\
\hline$C_{\text {price }}$ & $\begin{array}{c}\text { Sale of electricity prices } \\
\text { yuan/(kw.h) }\end{array}$ & 0.5 \\
\hline$\lambda$ & $\begin{array}{c}\text { Line average failure rate } \\
\text { /(times/(100km.a) }\end{array}$ & 0.73 \\
\hline$\beta$ & $\begin{array}{c}\text { Transmission line loss conversion } \\
\text { coefficient /10-6 }\end{array}$ & 57.39 \\
\hline
\end{tabular}

Table 2. Candidate Transmission Lines parameters

Parameters Meaning Numerical

\begin{tabular}{ll}
$c_{l 480}$ & $\begin{array}{l}\text { Per unit length of the project cost } \\
\text { of Rated power of } 480 \mathrm{MW} \\
\text { line/( Million yuan } / \mathrm{km})\end{array}$ \\
\hline
\end{tabular}

\begin{tabular}{|c|c|c|}
\hline$c_{l 600 l}$ & $\begin{array}{l}\text { Per unit length of the project cost } \\
\text { of rated power of } 600 \mathrm{MW} \text { line with } \\
\text { low failure rate } /(\text { Million yuan } / \mathrm{km})\end{array}$ & 30 \\
\hline$c_{l 600 h}$ & $\begin{array}{l}\text { Per unit length of the project cost } \\
\text { of rated power of } 600 \mathrm{MW} \text { line with } \\
\text { high failure rate } /(\text { Million yuan } \\
/ \mathrm{km})\end{array}$ & 28 \\
\hline$c_{l 700 l}$ & $\begin{array}{l}\text { Per unit length of the project cost } \\
\text { of rated power of } 700 \mathrm{MW} \text { line with } \\
\text { low failure rate /( Million yuan } / \mathrm{km})\end{array}$ & 40 \\
\hline$c_{l 700 h}$ & $\begin{array}{l}\text { Per unit length of the project cost } \\
\text { of rated power of } 700 \mathrm{MW} \text { line with } \\
\text { high failure rate /( Million yuan } \\
/ \mathrm{km})\end{array}$ & 38 \\
\hline$\beta_{600 l}$ & $\begin{array}{l}\text { Line failure rate of rated power of } \\
600 \mathrm{MW} \text { line with low failure rate } \\
/(\text { times } /(100 \mathrm{~km} . \mathrm{a}))\end{array}$ & 0.07 \\
\hline$\beta_{600 h}$ & $\begin{array}{l}\text { Line failure rate of rated power of } \\
600 \mathrm{MW} \text { line with high failure rate } \\
/(\text { times } /(100 \mathrm{~km} . \mathrm{a}))\end{array}$ & 0.13 \\
\hline$\beta_{700 l}$ & $\begin{array}{l}\text { Line failure rate of rated power of } \\
700 \mathrm{MW} \text { line with low failure rate } \\
/(\text { times } /(100 \mathrm{~km} . \mathrm{a}))\end{array}$ & 0.088 \\
\hline$\beta_{700 h}$ & $\begin{array}{l}\text { Line failure rate of rated power of } \\
700 \mathrm{MW} \text { line with high failure rate } \\
/(\text { times } /(100 \mathrm{~km} . \mathrm{a}))\end{array}$ & 0.15 \\
\hline
\end{tabular}

Set annual load operation curve shape does not change, the annual load growth rate is $2 \%$, the reference value is 100MW. First of all, statistics and find severely overloaded line in all states and the proportion of each overloaded lines, the results in Table 3 , table line mark is represented by bus number from both sides of lines.

Table3. The simulation results of heavy haul line searching

\begin{tabular}{ll}
\hline Overloaded line label & Proportion $(\%)$ \\
\hline $1-2$ & 4.67 \\
\hline $4-5$ & 2.87 \\
\hline $4-14$ & 8.97 \\
\hline $6-11$ & 38.75 \\
\hline $16-21$ & 12.84 \\
\hline $21-22$ & 7.78 \\
\hline $26-29$ & 5.23 \\
\hline $28-29$ & 15.45 \\
\hline Others & 3.43 \\
\hline
\end{tabular}

Table 3 shows the most serious overloaded lines is line $6-11$, followed by the line $28-29$, line $16-21$, more than $10 \%$ respectively, three accounted for $67.04 \%$ of the total proportion, so adopt renovation planning for these three lines, according to the three lines of different transforming, this paper divide into many kinds of scheme, simulate analysis and calculate each programs LCC, to find the optimal solution, the results are shown in Table 4 discussion program. Because $C D$ including demolition disposal of labor, equipment costs and transportation fees, the paper set device processing waste receipts offset these costs, so the cost of decommissioning the disposal of zero, there is no discussion in the table, $C M$ considered only three lines involved, Because the rest of the line $C M$ in 
the three scheme is basically same, so also not reflected in the table, Failure costs involved EENS data shown as table 5 .

Scheme of A1 is not to take any reform measures, as compared to other schemes. Scheme of A2 is 6-11 line expansion into the low failure rate of $600 \mathrm{MW}$ rated power transmission lines, line 28-2 and 16-21 expansion to the low failure rate of $700 \mathrm{MW}$ rated power transmission lines; Scheme of A3 is line 6-11 expansion to high failure rate of $600 \mathrm{MW}$ rated power transmission lines, line $28-2$ and the capacity of $16-21$ to the high failure rate of $700 \mathrm{MW}$ rated power transmission lines;

Table 4. Scheme comparison results

$C I$ / $C O$ / CM / CF / LCC,

SchemeMillion Million Million Million Million

\begin{tabular}{llllll}
\multicolumn{2}{c}{ yuan } & yuan & yuan & yuan & yuan \\
\hline A1 & 0 & 6824.85 & 367.76 & 5897.33 & 13089.94 \\
\hline A2 & 7857.93 & 6824.85 & 535.83 & 3785.01 & 19003.62 \\
\hline A3 & 7445.03 & 6824.85 & 507.67 & 4214.39 & 18991.94 \\
\hline \multicolumn{5}{c}{ Table 5. The scheme of expected energy not supplied } \\
\hline Scheme & A1 & (MW) & A2 (MW) & A3 & $(\mathrm{MW})$ \\
\hline 1year & 13782.564 & 7745.608 & 8769.482 \\
\hline 2year & 17832.438 & 12152.908 & 13862.763 \\
\hline 3year & 24448.559 & 16728.448 & 18368.124 \\
\hline 4year & 29981.546 & 20564.813 & 22514.239 \\
\hline 5year & 40473.939 & 24070.921 & 26995.582 \\
\hline total & 126519.046 & 81262.698 & 90510.19 \\
\hline
\end{tabular}

Firstly, compare the two rehabilitation programs that can be seen by comparing Table 4, A2 LCC and A3 LCC compared to a difference of 116800 yuan which is very close. Although the scheme of A3 investment cost is lower than the scheme of $\mathrm{A} 2$, in the cost of failure is greater than that in $\mathrm{A} 2$ scheme, then expected energy not supplied of A2 is less than A1 for 9247.492MW, the average annual reduction of the expected energy not supplied is $1849.50 \mathrm{MW}$, which is a significant figure. Further analysis and comparison program A1, the reason of A1 LCC is lower is that there are no extra investment costs, But from tables 4 and 5 can see that the power supply and power transmission network reliability is poor, athough the cost of the program is cheaper compared to rehabilitation programs, does not meet our power grid corp taking economic construction as the goal of the national policy, also do not conform to the electric power enterprise committing to reliable operation and the purpose of customers.

To sum up, considerong from the LCC cost, improving power and transmission network operation reliability, should choose the scheme of A2.

\section{CONCLUSIONS}

In this paper, the transmission line planning model is established based on the theory of LCC, considering the investment, operation cost, maintenance cost, failure cost, scrap cost of initial load and transmission line, making the planning scheme not only satisfies the optimal economic, but also the reliability level of planning scheme; Proposed to use the Monte Carlo simulation method and the DC power flow load shedding model, not only improve the speed, compared to other articles also improve the accuracy; Asset life-cycle management approach proposed can be used as the important part of promotion of lean management and scientific decision-making level, to drive the electric power enterprise asset management concept innovation. Through numerical analysis of nodes running IEEE39 example, comparative study of development programs, draw conclusions that should choose a high cost of the program with low failure rate, proving the feasibility of this method.

\section{REFERENCES}

[1] ZHAO Guo-bo, LIU Tian-qi, LI Xing-yuan, CHEN Bin, "Power Transmission System Planning Based on Grey Chance Constrained Programming,"Power System Technology, vol 33(1),2009,pp.2225.doi:10.13335/j.1000-3673.pst.2009.01.003

[2] ZENG Ming, LÜ Chun-quan, QIU Liu-qing, TIAN Kuo,”A Demand-Side Response-Based Transmission Planning Model With Grid-Connected Wind Farms"Power System Technology, vol 35(4),2011,pp.129-134.doi:10.13335/j.1000-3673.pst.2011.04.027

[3] Zheng Jing, Wen Fu-suan, Li Li, Wang Ke, Gao Chao,'Transmission System Expansion Planning Considering Combied Operation of Wind Farms and Energy Storage Systems",Automation of Electric Power Systems, vol 37(1),2013,pp.135-141. doi: 10.7500/AEPS201206068.

[4] Huang Yu-chun, Yang Jia-jia, Wen Fu-shuan, Wang Chao, Zhang Jing, Xu Qi-feng,'Reliability Evaluation for Distribution System with Distributed Generations Considering Reconfiguration",Automation of Electric Power Systems,vol 37(4),2013,pp.28-34. doi:10.7500/AEPS201206230

[5] ZHOU Jinhui,YU Yixin,WANG Fei,ZENG Yuan," Short Term Integrated Expansion Planning for Transmission Network Considering Static Security Risk", Automation of Electric Power Systems, vol 34(6),2010, pp.22-25.

[6] Ingo Jeromin, Gerd Balzer, Jürgen Backes, Richard Huber,’Life Cycle Cost Analysis of transmission and distribution systems",IEEE Bucharest Power Tech Conference, 2009, Bucharest, Romania.doi: 10.1109/PTC.2009.5282168

[7] Laxman Y. Waghmode, Anil D. Sahasrabudhe,"Product Life Cycle Cost Modelling - A Suggested Framework". First International Conference on Emerging Trends in Engineering and Technology, 2008, 7:745-748. doi: 10.1109/ICETET.2008.27

[8] LIU Jian, ZHANG Yong, DU Zh-i ye1, RUAN Jiang-jun, LIU Kai pei,"Life Cycle Cost Sensitivity Analysis in AC Transmission Lines Design“,High Voltage Engineering,vol 36(6),2010,pp.15541558,vol 10.13336/j.1003-6520.hve.2010.06.035

[9] LIU Haisheng, LIU Jian, LI Jun, WANG Hanguang, GUO Li, GUO Wei,"Conductors Selection of UHVDC Transmission Lines Based on Life Cycle Cost", High Voltage Engineering, vol 38(2),2012,pp.310-315,doi:10.3969/j.issn.1003-6520.2012.02.008

[10] XU Yu-qin, REN Zheng, ZHAN Xiang-ling, GENG Jiang-hai, XIE Qing,"Life cycle cost model and comprehensive sensitivityanalysis of power transformer",Journal of North China Electric Power University,vol41(6),2014,pp.80-86. doi: 10. 3969 /j. ISSN. 1007 2691.2014.06.13 